\title{
Fast electrochemical reactions during the anodization of platinum electrodes in aqueous solutions. Detection of a reversible charge storage process at platinum-oxide-coated electrodes
}

\author{
A.E. Bolzán and A.J. Arvia \\ Instituto de Incestigaciones Fisicoquímicas Teóricas y Aplicadas (INIFTA), Facultad de Ciencias Exactas, \\ Unicersidad Nacional de La Plata, Sucursal 4, Casilla de Correo 16, (1900) La Plata (Argentina)
}

(Received 29 January 1992; in revised form 2 June 1992)

\begin{abstract}
Fast electrochemical reactions at platinum and platinum-oxide-coated electrodes immersed in aqueous electrolytes can be observed by means of the triangularly modulated triangular potential sweep technique. The surface redox process commences at about $0.75 \mathrm{~V}$ in acid solution and is related to the initial oxygen-containing species reversibly electroadsorbed on platinum. Platinum coated with an oxide layer formed through a potentiodynamic routine presents a reversible charge storage process at about $1.6 \mathrm{~V}$ in acid solution. The corresponding reaction can be interpreted as a reversible redox couple involving $\mathrm{Pt}(\mathrm{II})-\mathrm{Pt}(\mathrm{IV})$ and proton injection in the platinum oxide matrix. The charge contribution of the second redox system is smaller than the total oxide charge accumulated on the substrate. Both fast redox systems appear also in base solutions.
\end{abstract}

\section{INTRODUCTION}

A number of oxygen-containing species can be formed through anodization of platinum in aqueous electrolytes. Some of these processes, implying charge and proton transfer, behave as fast electrochemical reactions, whereas others appear to be highly irreversible ones. The initial reaction is the reversible electroadsorption of hydroxyl species, which constitutes the first stage in oxide formation on this metal [1]. This reaction commences at about $0.75 \mathrm{~V}$ in acid solutions. The $\mathrm{OH}$-electroadsorbed layer undergoes different aging processes [2-5], yielding at potentials more positive than $0.9 \mathrm{~V}$ a more stable oxide layer. These aging processes have been interpreted as a place exchange mechanism [2-5]. 
The characteristics of the oxide layer grown on platinum depend on the applied potential routine. Oxide layer growth at a constant potential of about $2.00 \mathrm{~V}$ implies the formation of at least two platinum oxide phases, denoted $\alpha-\mathrm{PtO}_{2}$ and $\beta-\mathrm{PtO}_{2}$ [6-8]. The voltammetric electroreduction of $\alpha-\mathrm{PtO}_{2}$ in acid solution occurs in the 0.8-0.4 V range, whereas that of $\beta-\mathrm{PtO}_{2}$ takes place in the $0.4-0.05 \mathrm{~V}$ range [9]. It should be noted that both processes are characterized by complex voltammetric peaks, which suggests that the composition of both phases is not entirely uniform. The thickness of $\alpha-\mathrm{PtO}_{2}$ increases with time but reaches a limiting thickness of about $3.0 \pm 0.5 \mathrm{~nm}$, as concluded from voltammetric [9] and ellipsometric [8] measurements, in contrast to $\beta-\mathrm{PtO}_{2}$ whose thickness increases linearly with time [8].

Alternatively, when a vigorous periodic potential cycling under appropriate conditions is applied to a platinum electrode immersed in aqueous electrolyte solutions, a platinum oxide layer can be accumulated which is described as a hydrous platinum oxide layer [10,11]. The properties of this type of oxide layer as compared to those produced potentiostatically differ significantly in density, water content, thickness values attainable and potential-solution composition behaviour [12].

Fast reversible charge storage electrochemical reactions have been reported for oxide-coated iridium [13-17], rhodium [18,19] and palladium $[20,21]$ electrodes, the first metal being the most extensively studied owing to its application in the field of electrochromic displays. In contrast, for the case of platinum the appearance of reversible charge storage current peaks is far from proven.

The present work examines the fast electrochemical systems formed at platinum electrodes in both acid and base solutions in different potential regions by using the triangularly modulated linear or triangular potential sweep technique. The appearance of a first redox system on platinum associated with the early stages of $\mathrm{O}$ atom electroadsorption is confirmed, but attention is focused on a fast redox system which appears at potentials preceding the threshold potential of the oxygen evolution reaction (OER). The behaviour of this system resembles to some extent that of systems previously described for other anodically treated noble metal electrodes. The optimal conditions for the appearance of the fast redox system at about $1.6 \mathrm{~V}$ are described. The presence of this type of redox system in anodized noble metals is important for theories of oxide layer growth and electrocatalysis of various reactions on oxide-coated noble metal electrodes [12,22,23].

\section{EXPERIMENTAL}

The working electrode consisted of a platinum wire (Johnson-Matthey, 99.998\% purity, $0.34 \mathrm{~cm}^{2}$ geometric area and $1.18 \mathrm{~cm}^{2}$ real area as calculated from the $\mathrm{H}$ atom sorption voltammetric charge [1]) sealed to a glass tube. Prior to cach experiment the working electrode was mechanically polished with an aqueous suspension of $\mathrm{Al}_{2} \mathrm{O}_{3} 1 \mu \mathrm{m}$ grit. The counterelectrode was a large platinum spiral and a reversible hydrogen electrode (RHE) in the same solution was used as the 
reference. The latter was connected through a Luggin-Haber capillary tip. Potentials in the text are referred to the RHE scale.

Working solutions of $1 \mathrm{M} \mathrm{H}_{2} \mathrm{SO}_{4}, 1 \mathrm{M} \mathrm{HClO}_{4}$ and $1 \mathrm{M} \mathrm{NaOH}$ were prepared from Merck (p.a.) chemicals and Milli-Q* water and used under purified $\mathrm{N}_{2}$. Runs were made at $25^{\circ} \mathrm{C}$. The electrochemical set-up was the same as described elsewhere [20,21].

Fast redox systems during positive and negative potential scans were detected through the triangularly modulated linear or triangular potential sweep (TMTPS) technique. This technique, which was introduced a few decades ago [24] to study adsorbates and co-adsorbates, is adaptable for discovering fast processes participating in the formation of metal oxides at the submonolayer and monolayer levels at noble metal electrodes [20,25-27]. Details of the technique are given in the literature [24,28]. Briefly, it consists of modulating a slow triangular potential scan with a relatively fast triangular potential sweep of small amplitude. The latter provides a sequence of voltammograms of the reacting system superimposed on the current-potential display related to the slow potential scan. The shape of the current-potential envelope depends on the rate of the electrochemical reaction involving different species which can be formed along the slow potential scan [28]. The degree of coupling between the potential perturbation and the rate of the electrochemical reaction can be changed by adjusting the frequency $(f)$ and amplitude $\left(A_{\mathrm{m}}\right)$ of the modulating potential. In this way, not only can fast redox processes be detected, but also co-adsorbed species can be differentiated by choosing the appropriate perturbing potential characteristics [28]. For the present work $A_{\mathrm{m}}$ and $f$ were adjusted to $0.040 \mathrm{~V}$ and $1 \mathrm{kHz}$ respectively. The latter was found to be the lowest value providing a satisfactory resolution in the TMTPS voltammograms resulting from runs in which the modulating frequency was varied between 0.1 and $3 \mathrm{kHz}$.

RESULTS

\section{Conventional and TMTPS voltammetry data}

A conventional voltammogram of platinum in $1 \mathrm{M} \mathrm{H}_{2} \mathrm{SO}_{4}$ run between 0.05 and $1.5 \mathrm{~V}$ at $0.3 \mathrm{~V} \mathrm{~s}^{-1}$ (Fig. 1) exhibits in the $0.05-0.40 \mathrm{~V}$ range the current peaks related to $\mathrm{H}$ adatom electrosorption-electrodesorption reactions [1], and at potentials greater than $0.7 \mathrm{~V}$ two ill-defined current peaks related to the initial stages of oxygen monolayer electroformation. These peaks are followed by a current plateau which extends up to the threshold potential of the OER. The relatively large cathodic current peak at about $0.72 \mathrm{~V}$ corresponds to the electroreduction of the oxide layer built up between 0.7 and $1.50 \mathrm{~V}$. The greater the upper switching potential $\left(E_{\mathrm{a}}\right)$, the more negative is the location of this peak. The negative potential shift of the oxide electroreduction voltammetric peak becomes particularly large when $E_{\mathrm{a}}$ enters the OER potential region. In this case the diffusionlimiting current due to the electroreduction of traces of $\mathrm{O}_{2}$ dissolved in the 


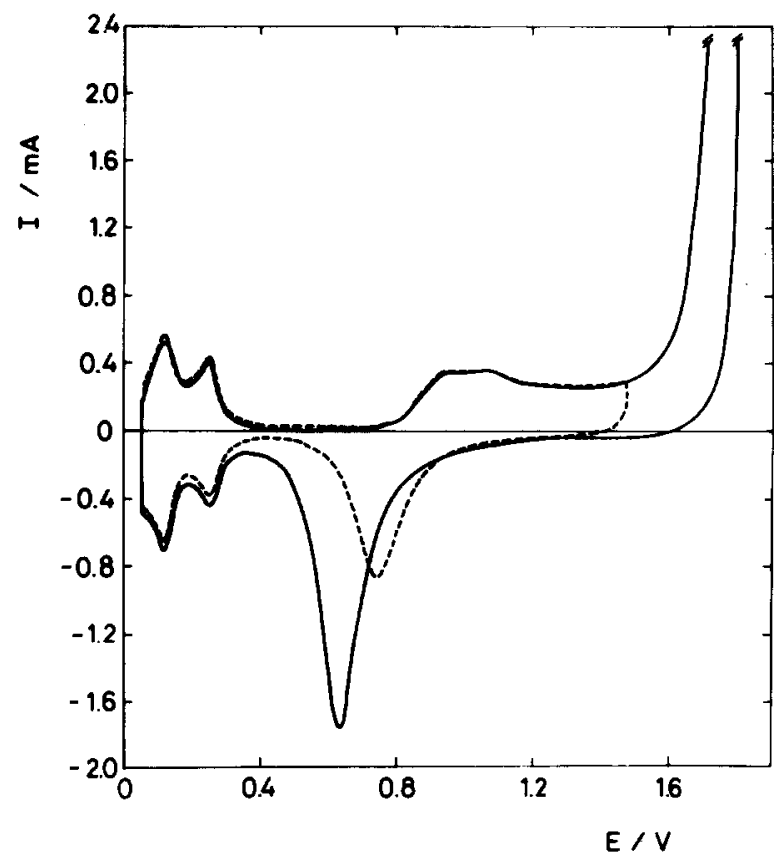

Fig. 1. Cyclic voltammograms of a smooth platinum electrode run between 0.05 and $1.50 \mathrm{~V}(\ldots \ldots)$ and between 0.05 and $2.00 \mathrm{~V}(\longrightarrow)$ at $v=0.3 \mathrm{~V} \mathrm{~s}^{-1}$ in $1 \mathrm{M} \mathrm{H}_{2} \mathrm{SO}_{4}$.

solution modifies the voltammogram in the $\mathrm{H}$ adatom electrosorption potential region.

The TMTPS voltammogram of platinum in $1 \mathrm{M} \mathrm{H}_{2} \mathrm{SO}_{4}$ run in the positive potential direction (Fig. 2 (a)) shows a fast current response between 0.05 and 0.4 $\mathrm{V}$ due to $\mathrm{H}$ adatom electrosorption reactions which are beyond the scope of the present work, and an asymmetric pair of conjugated current peaks extending from 0.75 to $1.2 \mathrm{~V}$ which are assigned to the underpotential discharge of water [2-5,24]. At potentials of about $1.5 \mathrm{~V}$, i.c. a valuc close to the OER threshold potential, the TMTPS voltammogram exhibits a rather broad, ill-defined current envelope. On the other hand, the TMTPS voltammogram run in the negative potential direction (Fig. 2(b)) shows no clear-cut conjugated electrochemical reactions in the 0.8-1.4 $\mathrm{V}$ range, but a contribution of the irreversible $\mathrm{O}$ adatom electroreduction reaction at $0.6 \mathrm{~V}$. At potentials lower than $0.6 \mathrm{~V}$ the $\mathrm{H}$ adatom electrosorption reactions are observed again with the same characteristics already described.

The conventional voltammetric response of platinum in $1 \mathrm{M} \mathrm{H}_{2} \mathrm{SO}_{4}$ can be changed considerably via a prior fast repetitive oxidation-reduction cycling (ORC), each cycle involving the formation and electroreduction of a fraction of the platinum oxide monolayer (ORC treatment) [4]. For this purpose the upper $\left(E_{\mathrm{a}}^{\prime}\right)$ and lower $\left(E_{\mathrm{c}}^{\prime}\right)$ switching potentials were set to 2.00 and $0.95 \mathrm{~V}$ respectively. The 


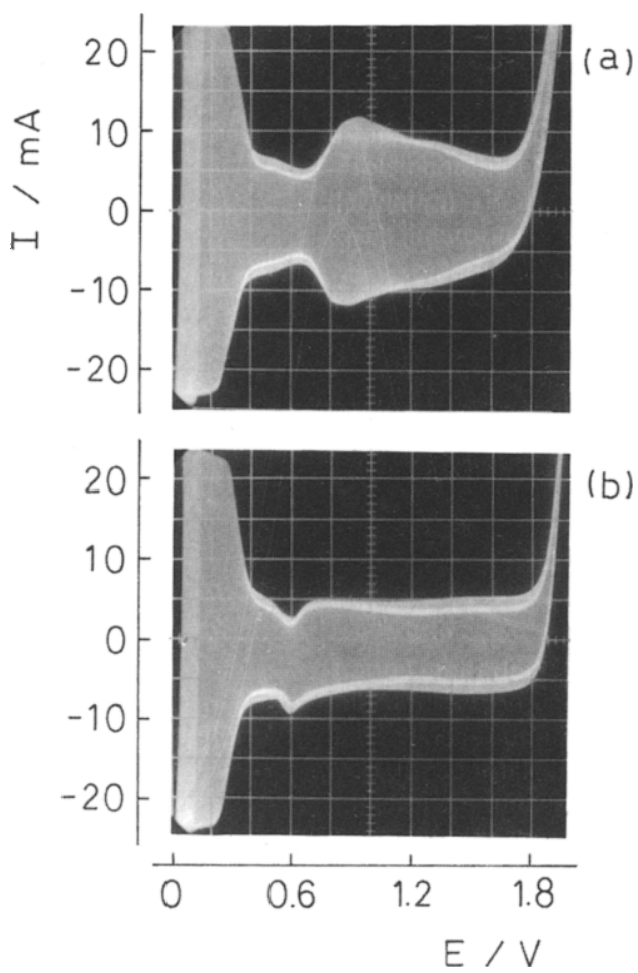

Fig. 2. TMTPS voltammograms of a smooth platinum electrode run between 0.05 and $2.00 \mathrm{~V}$ at $\iota=0.3$ $\mathrm{V} \mathrm{s}^{-1}\left(A_{\mathrm{m}}=0.04 \mathrm{~V}, f=1 \mathrm{kHz}\right)$ : (a) positive potential scan; (b) negative potential scan.

voltammograms recorded after the ORC treatment depended upon $\tau$, the duration of the ORC treatment. Thus the voltammogram run at $v=0.3 \mathrm{~V} \mathrm{~s}^{-1}$ resulting after an ORC treatment comprising $E_{\mathrm{a}}^{\prime}=2.00 \mathrm{~V}, E_{\mathrm{c}}^{\prime}=0.95 \mathrm{~V}$ and $v=0.3 \mathrm{~V} \mathrm{~s}^{-1}$ shows that as $\tau$ is increased, the current contribution in the $0.95-1.6 \mathrm{~V}$ range decreases and the polarization of the OER increases (Fig. 3, dashed trace). Besides, for $\tau=60 \mathrm{~s}$ the voltammogram extended to $0.05 \mathrm{~V}$ displays a single sharp and large electroreduction peak at about $0.5 \mathrm{~V}$ which increases in height and shifts negatively as $\tau$ is increased. In this case the electroreduction voltammogram resembles that recorded for the oxide layer denoted in the literature as $\alpha-\mathrm{PtO}_{2}$ [9]. Furthermore, there is an electroreduction limiting current extending from about $0.8 \mathrm{~V}$ downwards (Fig. 3, full trace) due to residual $\mathrm{O}_{2}$ formed at $2.00 \mathrm{~V}$ which overlaps the oxide layer electroreduction current and the electroadsorption of $\mathbf{H}$ atom currents. The TMTPS voltammogram run between 0.95 and $2.00 \mathrm{~V}$ exhibits a fast redox system (FRS) with a peak current contribution at about $1.6 \mathrm{~V}$, which can be enhanced as $\tau$ is increased (Figs. 4(a) and 4(b)).

A similar electrochemical response can be observed for platinum in $1 \mathrm{M} \mathrm{HClO}_{4}$ (Fig. 5(a)) and $1 \mathrm{M} \mathrm{NaOH}$ (Fig. 5(b)), although the composition of the solution 


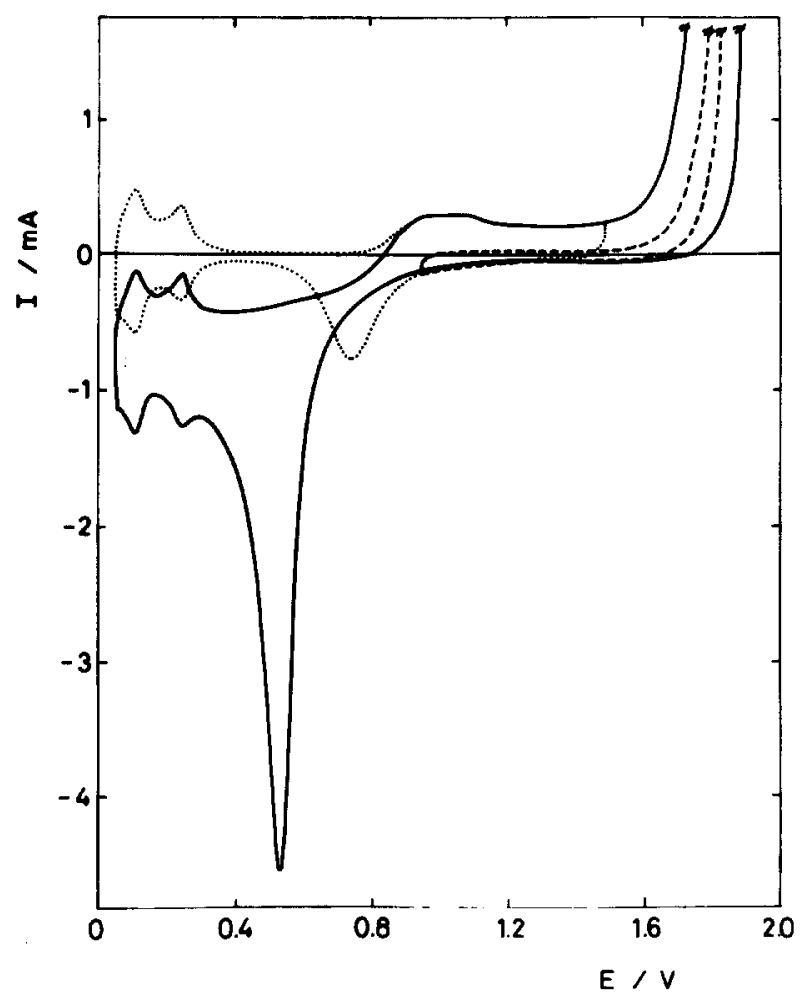

Fig. 3. Cyclic voltammograms of a smooth platinum electrode between 0.05 and $1.50 \mathrm{~V}(\cdots \cdots)$, between 0.05 and $2.00 \mathrm{~V}(\longrightarrow)$ and between 0.95 and $2.00 \mathrm{~V}(-\ldots)$ at $v=0.3 \mathrm{~V} \mathrm{~s}^{-1}$ in $1 \mathrm{M}$ $\mathrm{H}_{2} \mathrm{SO}_{4} \cdot \tau=60 \mathrm{~s}$.

influences the platinum oxide layer electrochemical formation as concluded from the corresponding current-potential profiles. Thus the FRS in $1 \mathrm{M} \mathrm{HClO}_{4}$ appears at potentials slightly more negative than in $1 \mathrm{M} \mathrm{H}_{2} \mathrm{SO}_{4}$, with rather little interference due to the OER. On the other hand, in $1 \mathrm{M} \mathrm{NaOH}$ the contribution of the FRS is considerably decreased (compare Figs. 5(a) and 5(b)).

The charge storage $(Q)$ related to the FRS as a function of $N$, the number of ORCs, was followed through the cathodic charge determined from the TMTPS voltammograms between $E_{\mathrm{a}}^{\prime}=2.00 \mathrm{~V}$ and $E_{\mathrm{c}}^{\prime}=0.95 \mathrm{~V}$. Linear relationships are obtained by plotting $Q$ against $\log N$ (Fig. 6). The slopes of the straight lines decrease in the order $1 \mathrm{M} \mathrm{HClO}_{4}>1 \mathrm{M} \mathrm{H}_{2} \mathrm{SO}_{4}>1 \mathrm{M} \mathrm{NaOH}$, but the extrapolation of these lines to $Q=0$ yields about the same $\left(N_{0}\right)$ value for the three electrolytes. This logarithmic growth rate law can be compared with that expected for oxide film growth where the Gibbs encrgy of activation increases linearly with thickness [29], as is discussed further on.

The stability of the FRS in $1 \mathrm{M} \mathrm{H}_{2} \mathrm{SO}_{4}$ was also studied by extending $E_{\mathrm{c}}^{\prime}$ progressively from 0.95 to $0.5 \mathrm{~V}$, a value close to the potential of the oxide 


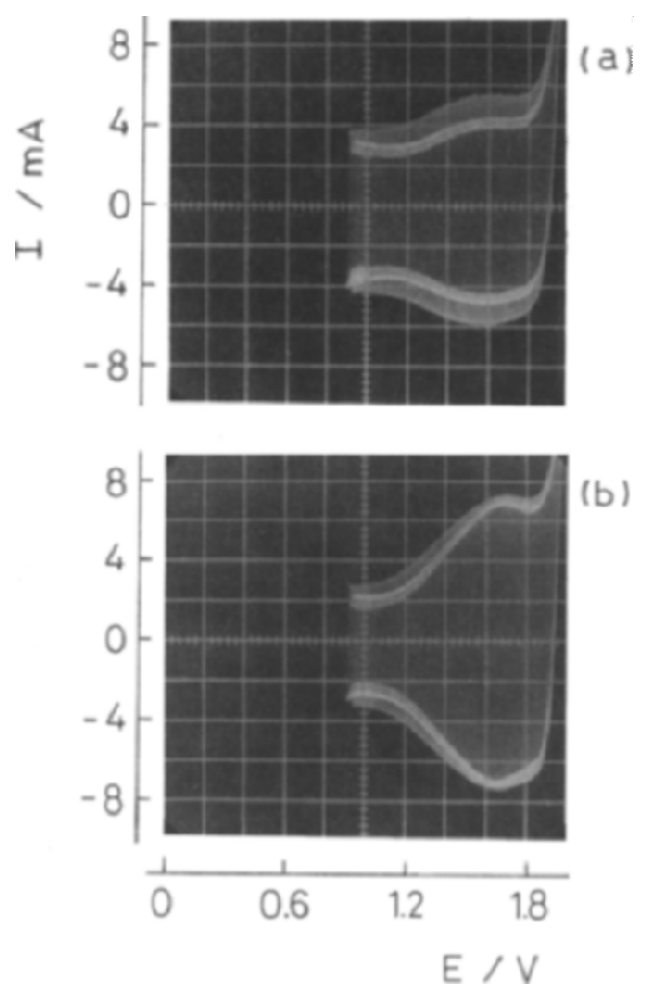

Fig. 4. TMTPS voltammograms of a smooth platinum electrode after cycling between 0.95 and $2.00 \mathrm{~V}$ at $l=0.3 \mathrm{~V} \mathrm{~s}^{-1}$ for (a) $\tau=30 \mathrm{~s}$ and (b) $\tau=3600 \mathrm{~s}\left(A_{\mathrm{m}}=0.04 \mathrm{~V}, f=1 \mathrm{kHz}\right)$ in $1 \mathrm{M} \mathrm{H}_{2} \mathrm{SO}_{4}$.

electroreduction current peak. These experiments showed that as soon as $E_{\mathrm{c}}^{\prime}$ reaches $0.5 \mathrm{~V}$, the current response of the FRS is no longer observed, in contrast to $1 \mathrm{M} \mathrm{NaOH}$ where the FRS can be observed after several cycles between 2.00 and $0.5 \mathrm{~V}$. In $1 \mathrm{M} \mathrm{NaOH}$ the anodic oxide layer electroreduction commences at a potential lower than in acid media.

The presence of the FRS was also detected in thicker platinum oxide layers grown under relatively fast ORC potentiodynamic treatments, e.g. between 0.58 and $2.2 \mathrm{~V}$ at $v=100 \mathrm{~V} \mathrm{~s}^{-1}$ for $60 \mathrm{~s}$ in $1 \mathrm{M} \mathrm{H}_{2} \mathrm{SO}_{4}$. The thick platinum oxide layer electroreduction was performed from $2.2 \mathrm{~V}$ downwards at $0.010 \mathrm{~V} \mathrm{~s}^{-1}$ and the corresponding electroreduction voltammogram was conveniently monitored in the differcnt potential ranges for scaling adequately the current response of the various stages of the electroreduction process. In this case the electroreduction voltammogram (Fig. 7, full trace) shows a broad and asymmetric cathodic peak at about $1.6 \mathrm{~V}$ preceding the oxygen monolayer electroreduction peak at $0.6 \mathrm{~V}$, the peak assigned to the electroreduction of the so-called $\alpha-\mathrm{PtO}_{3}[6,7,9]$, and another platinum oxide electroreduction complex peak in the $0.25-0.15 \mathrm{~V}$ range. The latter resembles the electroreduction peak assigned to $\beta-\mathrm{PtO}_{2}$ [9]. Likewise, the corre- 


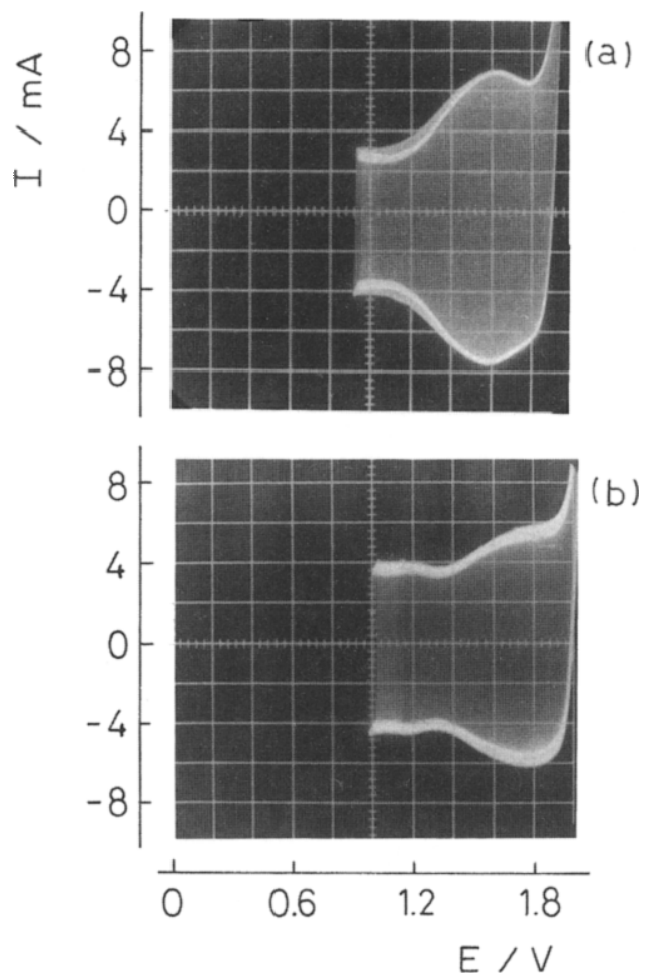

Fig. 5. TMTPS voltammograms of a smooth platinum electrode cycled between 0.95 and $2.00 \mathrm{~V}$ at $0.3 \mathrm{~V}$ $\mathrm{s}^{-1}$ in (a) $1 \mathrm{M} \mathrm{HClO}_{4}$ for $\tau=360 \mathrm{~s}$ and (b) $1 \mathrm{M} \mathrm{NaOH}$ for $\tau=1200 \mathrm{~s}\left(A_{\mathrm{m}}=0.04 \mathrm{~V}, f=1 \mathrm{kHz}\right)$.

sponding TMTPS voltammogram (Fig. 8) shows a pair of reversible peaks related to the FRS in the 1.6-1.8 V range, although in this case the envelope of the voltammogram becomes broader than that found for thin platinum oxide layers (Fig. 4).

The charge related to the FRS resulting in thicker platinum oxide layers (Fig. 7) increases with the number of ORCs run between $E_{\mathrm{c}}^{\prime}=0.58 \mathrm{~V}$ and $E_{\mathrm{a}}^{\prime}=2.2 \mathrm{~V}$ at $v=100 \mathrm{~V} \mathrm{~s}^{-1}$ and reaches a maximum value (about $0.72 \mathrm{mC} \mathrm{cm}^{-2}$ ) for 5500 cycles or thereabouts (Fig. 9). In any case the maximum charge density related to the FRS is always about one order of magnitude lower than the charge stored during the ORC as platinum oxide, as can be deduced from the corresponding electroreduction peaks [11]. It is interesting to note that the ascending branch of the charge vs. $N$ plot approaches a linear dependence with $N^{1 / 2}$ (Fig. 9, inset), whereas the descending branch presents a rather smooth decay.

In contrast to the easy formation of the FRS through fast ORC, such a system can hardly be observed under prolonged potentiostatic anodization conditions even at potentials as high as $3.00 \mathrm{~V}$ for $16 \mathrm{~h}$, i.e. the experimental conditions which were used for X-ray photoelectron spectroscopy (XPS) studies of the platinum oxide 


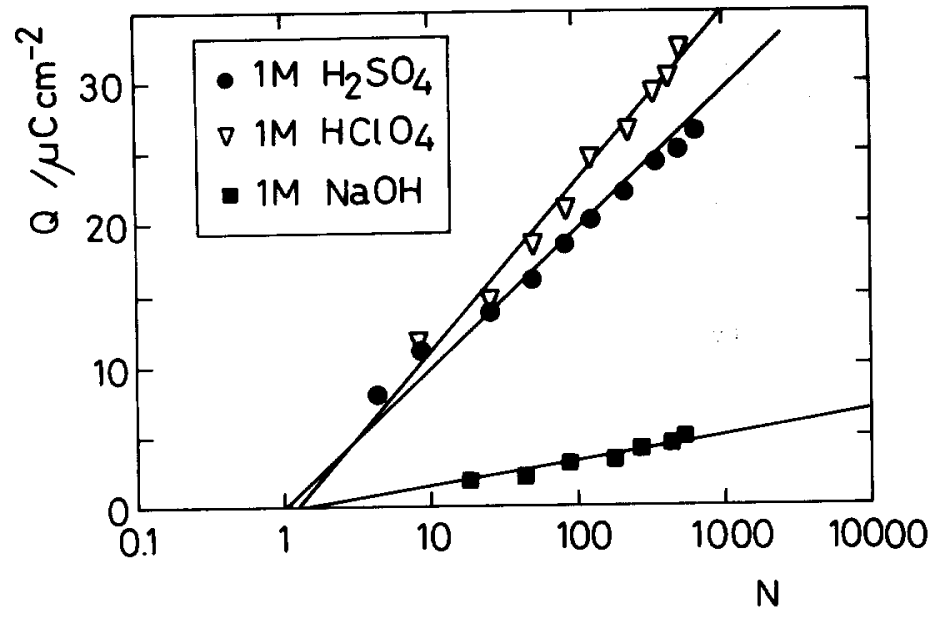

Fig. 6. Plots of $Q$, the cathodic charge, resulting from the TMTPS voltammetry for the FRS vs. $N$, the number of ORCs, in different electrolytes.

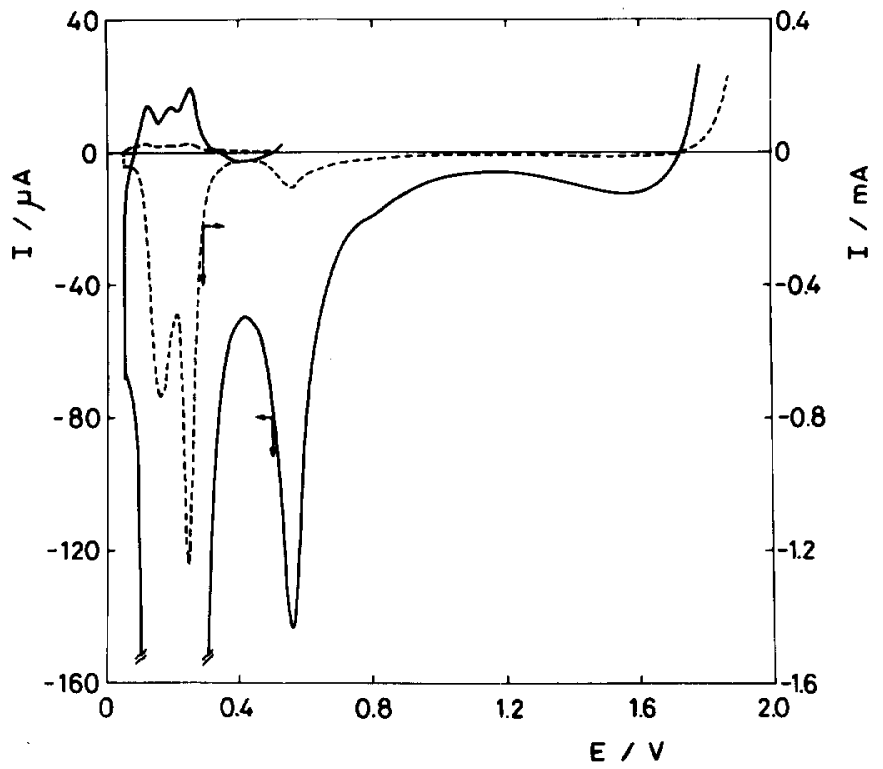

Fig. 7. Electroreduction voltammogram of a thick hydrous platinum oxide grown at $100 \mathrm{~V} \mathrm{~s}^{-1}$ between 0.58 and $2.2 \mathrm{~V}$ for $60 \mathrm{~s}$ at $l=0.010 \mathrm{~V} \mathrm{~s}^{-1}$ in $1 \mathrm{M} \mathrm{H}_{2} \mathrm{SO}_{4}$. Two current scales are used to emphasize the contributions of the different processes. 


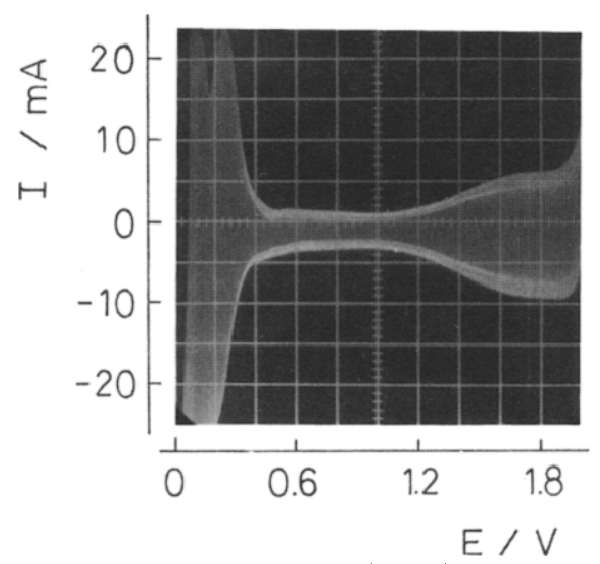

Fig. 8. TMTPS electroreduction voltammogram of a thick hydrous platinum oxide grown at $100 \mathrm{~V} \mathrm{~s}^{-1}$ between 0.58 and $2.2 \mathrm{~V}$ for $60 \mathrm{~s}$ at $t=0.1 \mathrm{~V} \mathrm{~s}^{-1}\left(A_{\mathrm{m}}=0.04 \mathrm{~V}, f=1 \mathrm{kHz}\right)$ in $1 \mathrm{M} \mathrm{H}_{2} \mathrm{SO}_{4}$.

layers $[30,31]$. In this case the voltammograms show only a current contribution at about 1.6 V several times lower than that obtained after the ORC treatment. These results are consistent with the fact that the potentiostatic anodization yields different types of oxide deposits as compared to those grown by potential cycling [12].

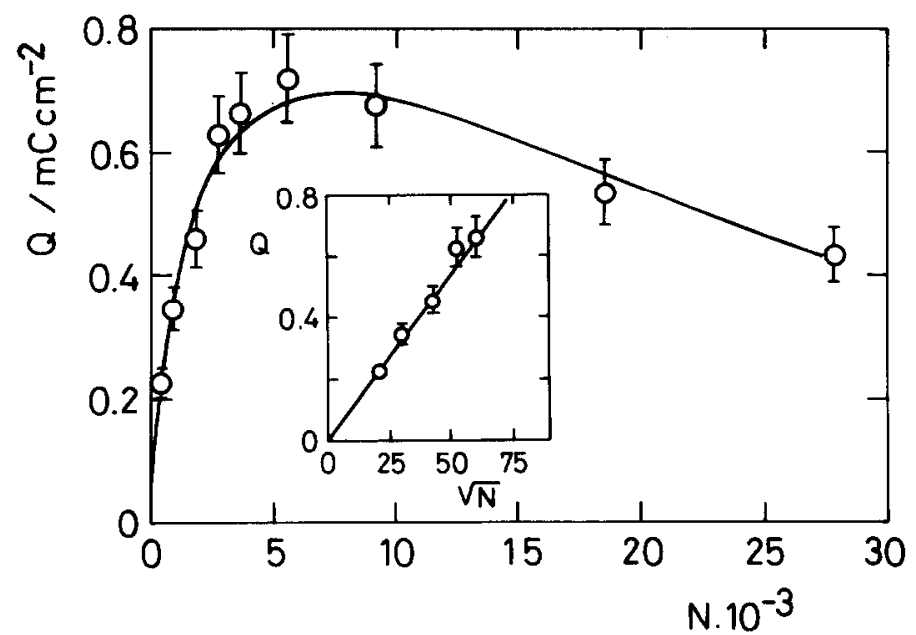

Fig. 9. Plot of $Q$, the FRS electroreduction charge, vs. $N$, the number of cycles; the hydrous platinum oxide layer was formed by potential cycling between 2.2 and $0.58 \mathrm{~V}$ at $c=100 \mathrm{~V} \mathrm{~s}^{-1}$ in $1 \mathrm{M} \mathrm{H}_{2} \mathrm{SO}_{4}: 0$, experimental data; - $\longrightarrow$, theoretical curve from eqn. (6), with $P_{1}=118.5 \mathrm{mC} \mathrm{cm}^{-2} \mathrm{cycle}^{\mathrm{l} / 2}$, $P_{2}=1.3 \times 10^{-4}$ cycle $^{-1}$ and $P_{3}=1.64 \times 10^{-3} \mathrm{mC} \mathrm{cm}^{-2}$ cycle $^{-1 / 2}$. 


\section{DISCUSSION}

Reversible systems at potentials greater than $0.6 \mathrm{~V}$

Let us consider the TMTPS voltammograms resulting from about $0.7 \mathrm{~V}$ upwards for polycrystalline platinum in acids, i.e. at potentials where oxygen-containing species are produced. The first reversible electrochemical system related to the initial stages of oxygen monolayer electroformation from the underpotential discharge of water is observed between 0.6 and $1.1 \mathrm{~V}$ or thereabouts (Fig. 2(a)). The corresponding surface reactions can be written formally as $[24,26]$

$[\mathrm{Pt}]+\mathrm{H}_{2} \mathrm{O} \rightleftharpoons[\mathrm{Pt}](\mathrm{OH})+\mathrm{H}^{+}+\mathrm{e}^{-}$

where the square brackets denote a platinum surface site and the parentheses stand for adsorbed species at the platinum site. The TMTPS voltammogram in the positive potential scan consists of at least two overlapping, broad current peaks (Fig. 2(a)) and the overall anodic-to-cathodic charge ratio resulting in the 0.6-1.1 $\mathrm{V}$ range approaches unity for $f=1 \mathrm{kHz}$. Furthermore, the charge densities related to the anodic and cathodic processes as estimated from Fig. 2(a) are close to those resulting in the same experiments for the $\mathrm{H}$-atom electroadsorption and electrodesorption processes. This fact suggests that under the conditions indicated in Fig. 2(a) the maximum platinum surface coverage by $\mathrm{OH}$ species becomes close to unity. Besides, the complex display of peaks associated with reaction (1) was ascribed to the participation of weakly and strongly bound $\mathrm{OH}$ species on platinum, as occurs for $\mathrm{H}$ adatom electrosorption processes on the same metal [1]. Then the complex display of peaks in the $0.6-1.1 \mathrm{~V}$ range can be attributed to the presence of different adsorption sites on platinum.

It has been demonstrated that reaction (1) is followed by a second irreversible electron-proton transfer reaction yielding an oxygen-containing surface species:

$[\mathrm{Pt}](\mathrm{OH}) \rightarrow[\mathrm{Pt}](\mathrm{O})+\mathrm{H}^{+}+\mathrm{e}^{-}$

Both $\mathrm{OH}$ - and oxygen-containing surface species on platinum undergo rapid aging, particularly when the applied potential is more positive than $0.9 \mathrm{~V}$. These aging processes are thought to occur through a place exchange mechanism which can be represented by the reactions $[1,7]$

$$
\begin{aligned}
{[\mathrm{Pt}](\mathrm{OH}) } & \rightarrow(\mathrm{OH})[\mathrm{Pt}] \\
{[\mathrm{Pt}](\mathrm{O}) } & \rightarrow(\mathrm{O})[\mathrm{Pt}]
\end{aligned}
$$

These reactions leave the possibility of further oxide growth on the platinum substrate exceeding the monolayer level.

The irreversible electrochemical behaviour of the surface species produced during the positive potential scan at $f=1 \mathrm{kHz}$ up to upper switching potentials more positive than $1.8 \mathrm{~V}$ can be seen in Fig. 2(b). In this case the anodic-to-cathodic charge ratio derived from the TMTPS voltammogram becomes appreciably smaller than unity and the symmetry of the current-potential contours in the 0.6-1.1 V 
range with respect to the zero-current baseline becomes considerably distorted. Accordingly, the fast redox process taking place in the 0.6-1.1 V range should involve a bare platinum surface and the first layer of water molecules as reactants, leading to the formation of $\mathrm{OH}$ - or oxygen-containing species at either the submonolayer or monolayer level.

The TMTPS voltammograms (Figs. 4 and 5) also show a second reversible system (FRS) at about $1.6 \mathrm{~V}$, i.e. in a potential range just preceding the threshold potential of the OER, which is formed simultaneously with the growth of the platinum oxide layer. This type of fast electrochemical reaction has been found for other noble metals such as iridium [13-15,32], rhodium [18,19] and palladium $[20,21]$ in nearly the same potential range. However, in contrast to these metals, for platinum the appearance of the FRS and the corresponding charge storage effect are produced exclusively through a fast ORC treatment.

The appearance of the FRS is observed for platinum electrodes coated with thin (thickness less than $2 \mathrm{~nm}$ ) oxide layers (hereafter denoted $\alpha$-PtO $\mathrm{P}_{2}$-type layers) and with thick (thickness greater than $5 \mathrm{~nm}$ ) oxide layers (hereafter denoted $(\alpha+\beta)$ $\mathrm{PtO}_{2}$-type layers). The $(\alpha+\beta)-\mathrm{PtO}_{2}$ layers produced at a constant potential have been described as a duplex anodic layer structure. The thickness of the $\alpha-\mathrm{PtO}_{2}$ reaches a limiting value which at a constant potential in $1 \mathrm{M} \mathrm{H}_{2} \mathrm{SO}_{4}$ is about $3 \mathrm{~nm}$ [8]. Likewise, after a prolonged anodization the thickness of the $\alpha$-PtO becomes negligible compared with that of the $\beta-\mathrm{PtO}_{2}$-type layer $[8,9,11,12]$.

For both types of platinum oxide films produced through ORC, the second fast electrochemical system can be explained in terms of different oxidation states of platinum species in the anodically formed platinum oxide matrix as discussed further on.

Kinetics of the charge storage process

Results have shown that the simultaneous formation of a platinum oxide layer and the FRS can be promoted by the application of appropriate potential-cycling routines to a platinum electrode immersed in aqueous electrolytes. Likewise, different kinetic behaviours for the formation of the FRS can be distinguished depending on whether an $\alpha$ - $\mathrm{PtO}_{2}$-type or an $(\alpha+\beta)-\mathrm{PtO}_{2}$-type layer has been formed. In the former case (Fig. 6) the charge storage related to the FRS obeys a logarithmic law, whereas in the latter case (Fig. 9) it follows a bell-shaped law. It has recently been observed that the potentiostatic growth of oxide films on platinum in $0.5 \mathrm{M} \mathrm{H}_{2} \mathrm{SO}_{4}$ at $25^{\circ} \mathrm{C}$ in the $1.8-2.3 \mathrm{~V}$ range obeys a logarithmic law [9].

The logarithmic law for the charge storage related to the FRS in thin $\alpha-\mathrm{PtO}_{2}-$ type layers contains an induction time $t_{\mathrm{i}}$, suggesting that a certain amount of platinum oxide has to be formed before the appearance of the FRS can be detected. In principle, the value of $t_{\mathrm{i}}$ appears to be independent of the solution composition. 
For a platinum electrode coated with an aged $\mathrm{O}$ atom monolayer, the oxide layer growth initiates at about $1.4 \mathrm{~V}$ through a reaction such as

$$
(\mathrm{O})[\mathrm{Pt}]+\mathrm{H}_{2} \mathrm{O} \rightarrow\{(\mathrm{O})[\mathrm{Pt}](\mathrm{O})\}+2 \mathrm{H}^{+}+2 \mathrm{e}^{-}
$$

where the braces denote a precursor of the $\alpha$-PtO ${ }_{2}$-type phase growth at the electrode surface. Probably the induction time could be related to the time for producing the minimum amount of this oxide required as a matrix to allocate the FRS. Despite the fact that the $\alpha-\mathrm{PtO}_{2}$ layer produced at a constant potential may differ from the $\alpha-\mathrm{PtO}_{2}$-type layer formed through the ORC treatment, there is a qualitative coincidence in the kinetic behaviour of the two systems, which suggests that the accumulation of the FRS in the oxide matrix is governed by the thickening of the oxide layer. Accordingly, the logarithmic kinetic law can be explained through a place exchange mechanism at the oxide phase, provided that for $t>t_{\mathrm{i}}$, in the range of a few oxide layers, the energy of activation for ion movement in the oxide depends on the oxide layer thickness [29].

On the other hand, under more severe conditions, i.e. a fast potential cycling with $E_{\mathrm{a}}>2.00 \mathrm{~V}$ (Fig. 9), the formation of the FRS is accompanied by the growth of a relatively thick $(\alpha+\beta)-\mathrm{PtO}_{2}$-type layer. The outer part ( $\beta$ - $\mathrm{PtO}_{2}$-type layer) of the composite layer resulting from the ORC treatment is usually described as a hydrous platinum oxide layer [12]. In this case the voltammetric results (Figs. 3 and 7) agree qualitatively with earlier potentiostatic anodic $\mathrm{PtO}_{2}$ formation data, since the amount of $\alpha-\mathrm{PtO}_{2}$-type layer becomes nearly the same for either $E_{\mathrm{a}}=2.0$ or $2.2 \mathrm{~V}$. Therefore, when the ORC treatment extends up to $E_{\mathrm{a}}=2.2 \mathrm{~V}$, the competing processes are principally the growth of the $\beta-\mathrm{PtO}_{2}$-type layer, i.e. a hydrous platinum oxide layer, and the FRS formation. Comparison of the $\beta-\mathrm{PtO}_{2}-$ type layer voltammetric electroreduction charge (Fig. 7) with the FRS charge (Fig. 9) indicates that when $E_{\mathrm{a}}=2.2 \mathrm{~V}$, the growth of the $\beta-\mathrm{PtO}_{2}$-type layer largely exceeds the FRS formation. Hence the kinetics of the FRS (Fig. 9) appears to be coupled to at least three different contributions, namely the formation of the $\beta-\mathrm{PtO}_{2}$-type layer, the blockage of the platinum surface for the $\beta-\mathrm{PtO}_{2}$-type layer growth and the dilution of the FRS in the growing oxide phase accompanied by the formation of $\mathrm{Pt}^{2+}$ soluble species at the oxide phase-acid interface. In this case the value of $t_{\mathrm{i}}$, which is related to the formation of the $\alpha$-PtO $\mathrm{O}_{2}$-type layer, becomes too small to be observed.

To interpret these complex processes, let us consider that the charge storage time is $t=N \tau_{\mathrm{a}}$, where $\tau_{\mathrm{a}}$ is the positive half-period of the potential perturbation. Otherwise, the hindrance to FRS accumulation due to the dilution and dissolution of the oxide layer constituents in the acid acts for a time $T$, the period of the ORC. Then $t_{\mathrm{d}}$, the dilution and dissolution time, can be taken as $t_{\mathrm{d}}=N T$, which for the symmetric potential signal results in $t_{\mathrm{d}}=2 N \tau_{\mathrm{a}}$. Accordingly, the kinetic law for FRS formation in the oxide layer becomes

$Q \propto \frac{P_{1}}{N^{1 / 2}}\left[1-\exp \left(-P_{2} N\right)\right]-P_{3} N^{1 / 2}$ 
where $Q$ is the apparent charge density related to the FRS, $N$ is the number of cycles and $P_{1}, P_{2}$ and $P_{3}$ are fitting parameters which are indicated in Fig. 9.

The right-hand side of eqn. (6) contains the FRS growth term which changes with $N^{-1 / 2}$, corrected for the surface blockage factor $1-\exp \left(-P_{2} N\right)$, and an FRS disappearance term which increases with $N^{1 / 2}$. On the basis of earlier results for rhodium [33] and platinum [34] which revealed a localized attack of the metal electrode surface in aqueous solutions after fast potential cycling at high positive potentials and the formation of soluble $\mathrm{Pt}^{2+}$ by anodizing platinum at potentials greater than $0.7 \mathrm{~V}$ as demonstrated through rotating ring-disk platinum electrode experiments [35], eqn. (6) can be interpreted as a 3D nucleation and growth mechanism under diffusion control related to the breakdown of the $\alpha-\mathrm{PtO}_{2}$-type layer leading to $\mathrm{Pt}^{4+}$ species which contribute principally to the growth of $\beta-\mathrm{PtO}_{2}$-type oxide and, to a lesser extent, to the FRS formation. The dilution of the FRS in the oxide matrix and the dissolution of platinum species at the oxide-solution interface behave as a diffusion-controlled process.

Equation (6) predicts that initially the formation of the FRS in the thick $(\alpha+\beta)-\mathrm{PtO}_{2}$-type layer obeys a linear $Q$ vs. $N^{1 / 2}$ plot (Fig. 9, inset). This type of rate law can also be derived from published data about the formation of hydrous oxide layers of platinum [10,11], iridium [36], palladium [37] and rhodium [38]. Therefore it is reasonable to conclude that in the case of thick platinum oxide layers formed by applying drastic potential routines, the kinetics of the FRS formation are also determined by the kinetics of the oxide phase growth.

The FRS growth rate in aqueous $\mathrm{NaOH}$ solutions is smaller than in acids, probably because in base solutions a more compact platinum oxide layer is formed, preventing the growth of a thick hydrous oxide layer containing the FRS.

\section{The likely electrochemical reaction related to the FRS}

According to XPS and electron energy loss spectroscopy (EELS) data, thick, compact platinum oxide layers formed at 3.00 and $2.3 \mathrm{~V}$ for $15 \mathrm{~h}$ [39] are related to the formation of ${ }^{\cdot} \mathrm{Pt}(\mathrm{OH})_{4}$ in acid [30,31,39] and $\mathrm{PtO}(\mathrm{OH})_{2}$ in base [40], whereas thinner layers obtained at potentials lower than $1.5 \mathrm{~V}$ apparently involve a single species, probably $\mathrm{Pt}(\mathrm{OH})_{4}$ [39]. Besides, EELS results revealed a weak O-O stretching band, although further work is required to estimate the actual contribution of peroxide species in the platinum oxide film [30]. On the other hand, thick, low density platinum oxide layers produced under appropriate conditions have been assigned preferentially to the $\left[\mathrm{Pt}(\mathrm{OH})_{6}\right]^{2-}$ structure $[11,12]$. The existence of platinum(IV) as required for the latter structure has been concluded from XPS data $[41,42]$.

The present results indicate that the FRS behaves as a redox system in bulk $\alpha$ - $\mathrm{PtO}_{2}$-type and $(\alpha+\beta)-\mathrm{PtO}_{2}$-type oxide layers, the potential range related to the presence of the FRS as seen through the TMTPS extending from 1.2 to $1.8 \mathrm{~V}$. According to thermodynamics [43], in this potential range the appearance of a redox couple involving platinum(II) and platinum(IV) species is possible. Then the 
TMTPS voltammetric response of the FRS can be described as a fast electrochemical reaction in the oxide phase, which can be represented as

$\left[\mathrm{Pt}^{2+}\right]_{\mathrm{b}} \rightleftharpoons\left[\mathrm{Pt}^{4+}\right]_{\mathrm{b}}+2 \mathrm{e}^{-}$

where the square brackets indicate reacting species in bulk oxide. Perhaps a more realistic equation for reaction (7) can be advanced:

$$
\begin{aligned}
& {\left[\left(x \mathrm{Pt}^{4+} / y \mathrm{Pt}^{2+}\right)\left(\mathrm{OH}^{-}\right)_{4 x+2 y} \cdot n \mathrm{H}_{2} \mathrm{O}\right]} \\
& \quad \rightleftharpoons\left[\left((x+1) \mathrm{Pt}^{4+} /(y-1) \mathrm{Pt}^{2+}\right)\left(\mathrm{OH}^{-}\right)_{4 x+2 y+2} \cdot(n-2) \mathrm{H}_{2} \mathrm{O}\right]+2 \mathrm{H}^{+}+2 \mathrm{e}^{-}
\end{aligned}
$$

Equation (8) emphasizes the simultaneous charge and proton transfers involved therein.

It should be noted, however, that although at present the values of the stoichiometric coefficients $x, y$ and $n$ cannot be established, data plotted in Fig. 9 indicate that the $x / y$ ratio remains nearly constant at least at the ascending branch of the $Q$ vs. $N$ plot. Further on, as the maximum value of $Q$ is exceeded, the $x / y$ ratio increases according to the thickness of the oxide layer. Equation (8), can also be extended to base solutions by considering $\mathrm{OH}^{-}$instead of $\mathrm{H}^{+}$as reactant ions [17].

The preceding interpretation is consistent with the mechanism proposed for charge storage reactions at iridium [13-15,32] and rhodium $[18,19]$ and the platinum oxide anodic layer structure established through XPS [31,39,41,42]. For iridium a reaction involving simultaneous proton injection and reversible change in the oxidation state of iridium ions in the oxide layer is supported by in situ IR [16] and probe beam deflection [17] measurements.

\section{CONCLUSIONS}

(1) TMTPS voltammetry confirms that the earlier stages of platinum anodization in acid and base solutions imply the reversible formation of adsorbed $\mathrm{OH}$ species at the monolayer level.

(2) When platinum electrodes are subjected to an ORC treatment reaching the potential region of the OER, the growth of a hydrous oxide layer accompanied by the formation of a highly reversible redox system can be observed in both acid and base solutions.

(3) The kinetics of the FRS growth depends on whether a thin or a thick hydrous platinum oxide layer is formed simultaneously. In the former case the reaction proceeds in the $\alpha$ - $\mathrm{PtO}_{2}$-type layer according to a logarithmic growth law, whereas in the latter case a bell-shaped rate equation is observed. In this case the platinum electrode is coated with an $(\alpha+\beta)$ - $\mathrm{PtO}_{2}$-type layer. In both cases it appears that the FRS growth rate is determined by the growth rate of the oxide layer. 
(4) The FRS can be related to a fast electron and proton transfer reaction involving platinum(II) and platinum(IV) oxidation levels in the bulk oxide.

\section{ACKNOWLEDGMENTS}

This work was supported financially by the Consejo Nacional de Investigaciones Científicas y Técnicas (CONICET) and the Comisión de Investigaciones Científicas de la Provincia de Buenos Aires (CIC).

\section{REFERENCES}

1 R. Woods, in A.J. Bard (Ed.), Electroanalytical Chemistry, Vol. 9, Marcel Dekker, New York, 1977.

2 H. Angerstein-Kozlowska, B.E. Conway and W.B.A. Sharp, J. Electroanal. Chem., 43 (1973) 9.

3 S. Gottesfeld and B.E. Conway, J. Chem. Soc., Faraday Trans. 1, 69 (1973) 1090.

4 A.J. Arvia, Isr. J. Chem., 18 (1975) 89.

5 H. Angerstein-Kozlowska and B.E. Conway, J. Electroanal. Chem., 95 (1979) 1.

6 S. Shibata, J. Electroanal. Chem., 89 (1978) 37.

7 A.T. Kuhn and T.H. Randle, J. Chem. Soc., Faraday Trans. 1, 81 (1985) 403.

8 S. Gottesfeld, G. Maia, J.B. Floriano, G. Tremiliosi-Filho, E.A. Ticianelli and E.R. Gonzalez, J. Electrochem. Soc., 138 (1991) 3219.

9 G. Tremiliosi-Filho, G. Jerkiewicz and B.E. Conway, Langmuir, 8 (1992) 658.

10 A.C. Chialvo, W.E. Triaca and A.J. Arvia, J. Electroanal. Chem., 146 (1983) 93.

11 L.D. Burke and M.B.C. Roche, J. Electroanal. Chem., 164 (1984) 315.

12 L.D. Burke, M.B. Roche and W.A. O'Leary, J. Appl. Electrochem., 18 (1988) 781.

13 R. Kötz, H. Neff and S. Stucki, J. Electrochem. Soc., 131 (1984) 72.

14 S. Gottesfeld, J. Electrochem. Soc., 127 (1980) 1922.

15 J.D.E. McIntyre, W.F. Peck and S. Nakahara, J. Electrochem. Soc., 127 (1980) 1264.

16 R.O. Lezna, K. Kunimatsu, T. Ohtsuka and N. Sato, J. Electrochem. Soc., 134 (1987) 3090.

17 R. Kötz, C. Barbero and O. Haas, J. Electroanal. Chem., 296 (1990) 37.

18 S. Gottesfeld, J. Electrochem. Soc., 127 (1980) 272.

19 C. Pallota, N.R. de Tacconi and A.J. Arvia, J. Electroanal. Chem., 122 (1981) 367.

20 A.E. Bolzan, A.C. Chialvo and A.J. Arvia, J. Electroanal. Chem, 179 (1984) 71.

21 A.E. Bolzan and A.J. Arvia, J. Electroanal. Chem., 322 (1992) 247.

22 B.E. Conway and T.C. Liu, Proc. R. Soc. Lond. A, 429 (1990) 375.

23 B.E. Conway and T.C. Liu, Langmuir, 6 (1990) 268.

24 B.E. Conway, H. Angerstein-Kozlowska, F.C. Ho, J. Klinger. B. MacDougall and S. Gottesfeld, Discuss. Faraday Soc., 56 (1973) 210.

25 J.O. Zerbino, N.R. de Tacconi and A.J. Arvia, J. Electrochem. Soc., 125 (1978) 255.

26 J.O. Zerbino, N.R. de Tacconi and A.J. Arvia, J. Electrochem. Soc., 125 (1978) 1266.

27 R.O. Lezna, N.R. de Tacconi and A.J. Arvia, J. Electroanal. Chem., 151 (1983) 193.

28 N.R. de Tacconi, J.O. Zerbino and A.J. Arvia, J. Electroanal. Chem., 79 (1977) 287.

29 M.A. Genshaw, in E. Gileadi (Ed.), Electrosorption, Plenum, New York, 1967, Chapter 4.

30 M. Peuckert and H. Ibach, Surf. Sci., 136 (1984) 319.

31 M. Peuckert, F.P. Coenen and H.P. Bonzel, Electrochim. Acta, 29 (1984) 1305.

32 L.D. Burke and D.P. Whelan, J. Electroanal. Chem., 124 (1981) 333.

33 E. Custidiano, S. Piovano, A.J. Arvia, A.C. Chialvo and M.I. Ipohorski, J. Electroanal. Chem., 221 (1987) 229.

34 A. Visintin, J.C. Canullo, W.E. Triaca and A.J. Arvia, J. Electroanal. Chem., 239 (1988) 67.

35 D.C. Johnson, D.T. Napp and S. Bruckenstein, Electrochim. Acta, 15 (1970) 1493.

36 L.D. Burke and K.A. Scannell, J. Electroanal. Chem., 175 (1984) 119. 
37 L.D. Burke and M.B.C. Roche, J. Electroanal. Chem., 186 (1985) 139.

38 L.D. Burke and E.J.M. O'Sullivan, J. Electroanal. Chem., 93 (1978) 11.

39 E. Rach and J. Heitbaum, Electrochim. Acta, 31 (1986) 477.

40 M. Peuckert, Electrochim. Acta, 29 (1984) 1315.

41 J.S. Hammond and N. Winograd, Electrochim. Acta, 78 (1977) 55.

42 G.C. Allen, P.M. Tucker, A. Capon and R. Parsons, Electrochim. Acta, 50 (1974) 335.

43 A.J. Bard, R. Parsons and J. Jordan (Eds.), Standard Potentials in Aqueous Solutions, Marcel Dekker, New York, 1985. 